\title{
Optimasi Produksi Dan Analisis Sensitivitas Menggunakan Algoritma Titik Interior (Studi Kasus: UP2K Melati, Prabumulih)
}

\author{
Asri Kuntari, Sisca Octarina, Endro Setyo Cahyono \\ Jurusan Matematika, Fakultas MIPA, Universitas Sriwijaya \\ Jln. Raya Palembang Prabumulih km 32 Inderalaya 30662 \\ Email: putri.asri29@yahoo.co.id ${ }^{1}$
}

\begin{abstract}
ABSTRAK
Algoritma titik interior merupakan suatu metode penyelesaian permasalahan pemrograman linear dengan mentransformasikan titik interior awal ke dalam daerah fisibel sehingga mencapai solusi optimal penyelesaian pemrograman linear. Penelitian ini bertujuan mengaplikasikan algoritma titik interior dalam menyelesaikan permasalahan optimasi produksi makanan ringan berbahan baku nanas pada UP2K Melati, Prabumulih. Keuntungan produksi dihitung dengan memperhatikan kendala bahan baku dan proses produksi. Berdasarkan hasil penelitian, diperoleh keuntungan maksimum produksi UP2K Melati sebesar Rp 710.987,00. Produk UP2K Melati yang diproduksi adalah dodol nanas sejumlah 43 kemasan/250 gram, manisan nanas sejumlah 65 kemasan/250 gram, dan keripik nanas sejumlah 128 kemasan/250 gram. Produk wajik nanas tidak direkomendasikan untuk diproduksi, karena produk wajik nanas tidak meningkatkan keuntungan produksi.
\end{abstract}

Kata Kunci: Algoritma Titik Interior, Pemrograman Linear, Analisis Sensitivitas.

\section{ABSTRACT}

Interior point algorithm is a method to solve linear programming by transforming the initial interior point into the feasible region to achieve the optimal solution. This research applied interior point algorithm to optimize the production of pineapple snack at UP2K Melati, Prabumulih. The production benefit was counted by considering the constraints and process of the product. Based on the result, the maximum benefit of production is Rp 710. 987,00. UP2K Melati should produce 43 packs/250 gram dodol nanas, 65 packs/250 gram manisan nanas, and 128 packs $/ 250$ gram keripik nanas. Wajik nanas is not recommended to produce, because wajik nanas does not increase the profits of production.

Keywords: Interior Point Algorithm, Linear Programming, Sensitivity Analysis

\section{Pendahuluan}

Persaingan industri di era globalisasi selalu berkaitan dengan upaya mengalokasikan sumber daya yang terbatas untuk memaksimalkan hasil industri sehingga mencapai tujuan optimal. Teknik perencanaan dalam manajemen industri sangat dibutuhkan agar menemukan kombinasi alternatif pemecahan optimum terhadap permasalahan industri [2].

Teknik perencanaan yang dapat mengatasi permasalahan industri antara lain pemrograman linear. Model pemrograman linear terdiri atas fungsi tujuan yang bersifat linear dari berbagai keputusan dan dibatasi oleh kendala-kendala produksi berupa pertidaksamaan linear. Penyelesaian optimal dari model pemrograman linear dapat ditemukan pada titik ekstrim dalam daerah fisibel [7].

Penyelesaian permasalahan pemrograman linear untuk dua variabel dapat menggunakan metode grafik, sedangkan penyelesaian untuk lebih dari dua variabel dapat menggunakan metode simpleks. Metode simpleks terkadang kurang efisien untuk jumlah variabel yang besar karena memerlukan waktu yang cukup lama dalam penemuan solusi dan terkadang terjadi kekeliruan melakukan pemilihan pivot dalam iterasi [6]. 
Alternatif untuk penyelesaian permasalahan pemrograman linear yang memiliki jumlah variabel yang sangat besar yaitu algoritma titik interior. Algoritma titik interior merupakan prosedur yang efisien dalam perhitungan dan iterasi untuk menembus titik interior daerah fisibel. Algoritma titik interior efektif untuk menyelesaikan permasalahan maksimasi dengan jumlah variabel sebanyak 93 dan jumlah kendala tidak kurang dari 12 akan mencapai solusi optimal pada iterasi ke-25 dibandingkan dengan menggunakan metode simpleks yang mencapai solusi pada iterasi ke-31 [8].

Algoritma titik interior dapat diterapkan pada permasalahan pemrograman linear serta permasalahan pemrograman kuadratik. Algoritma titik interior tepat digunakan dalam memilih kombinasi proyek yang memiliki keuntungan dan rencana kerja yang optimal pada perusahaan konveksi [1]. Selain itu, algoritma titik interior dapat diterapkan dalam pemrograman kuadratik [11].

Pengambilan studi kasus terhadap pengolahan nanas didasarkan karena produksi olahan nanas di Kota Prabumulih dihadapi dengan berbagai kendala aktivitas industri pengolahan yang terbatas. Upaya menjaga eksistensi buah nanas yaitu dengan mengolah nanas sebagai makanan ringan yang diproduksi berbagai unit kewirausahaan binaan Dinas Koperasi dan UKM Kota Prabumulih. Salah satu industri produk olahan nanas di Kota Prabumulih yaitu Unit Peningkatan Penghasilan Keluarga (UP2K) Melati yang mulai beroperasi memproduksi olahan nanas seperti dodol nanas, wajik nanas, manisan nanas, dan keripik nanas sejak tahun 2000 [5]. Berdasarkan latar belakang tersebut peneliti ingin mengaplikasikan algoritma titik interior pada optimasi produksi makanan ringan olahan nanas. Penyelesaian yang diperoleh dari algoritma titik interior dapat diuji kelayakan perubahannya secara analisis sensitivitas sehingga hasil optimal dapat diketahui batasan-batasan interval yang membuat solusi tetap optimal.

\section{Metode Penelitian}

Penelitian ini menggunakan data sekunder yang diperoleh dari Unit Peningkatan Pendapatan Keluarga (UP2K) Melati, Prabumulih, dan data primer yaitu data hasil observasi serta data perhitungan keuntungan penjualan tiap produk. Permasalahan pada penelitian ini dibatasi pada faktor kendala yang digunakan meliputi ketersediaan bahan baku pembuatan makanan ringan olahan nanas, harga jual tiap produk, dan biaya produksi. Data penjualan dan data produksi tiap produk makanan ringan berbahan baku nanas yang digunakan mulai dari Mei hingga Agustus 2014.

\subsection{Data Observasi}

Penelitian ini mengumpulkan data antara lain data ketersediaan bahan baku, harga jual tiap produk, proses produksi tiap produk, biaya produksi tiap produk, dan data penjualan dari bulan Mei-Agustus 2014. Data yang telah dikumpulkan tersebut sebagai kendala permasalahan optimasi produksi dan data hasil perhitungan keuntungan tiap produk sebagai fungsi tujuan dalam memaksimumkan keuntungan tiap produk.

\subsection{Variabel Penelitian}

Unit Peningkatan Penghasilan Keluarga (UP2K) Melati, Prabumulih memproduksi 4 jenis produk olahan nanas antara lain dodol nanas, wajik nanas, manisan nanas, dan keripik nanas. Produk olahan nanas tersebut diproduksi dengan berat satuan 250 gram per kemasan. Jenis produk olahan nanas didefinisikan sebagai variabel penelitian sebagai berikut:

$x_{1}$ adalah jumlah produk dodol nanas (kemasan 250 gram).

$x_{2}$ adalah jumlah produk wajik nanas (kemasan 250 gram).

$x_{3}$ adalah jumlah produk manisan nanas (kemasan 250 gram).

$x_{4}$ adalah jumlah produk keripik nanas (kemasan 250 gram).

\subsection{Pengolahan dan Analisis Data}

Tahapan pengolahan dan analisis data dimulai dengan mendeskripsikan data observasi yang telah dikumpulkan menjadi variabel penelitian. Variabel penelitian selanjutnya diformulasikan menjadi bentuk model pemrograman linear dengan fungsi 
tujuan untuk memaksimumkan keuntungan produksi tiap produk dan kendala dari ketersediaan bahan baku serta proses produksi.

Bentuk umum model pemrograman linear sebagai berikut :

Fungsi tujuan: Maks/Min $Z=c_{1} x_{1}+c_{2} x_{2}+c_{3} x_{3}+\cdots+c_{n} x_{n}$

Dengan kendala

$$
\begin{array}{ll}
a_{11} x_{1}+a_{12} x_{2}+\cdots+a_{1 n} x_{n} & (\leq,=, \geq) b_{1} \\
a_{21} x_{1}+a_{22} x_{2}+\cdots+a_{2 n} x_{n} & (\leq,=, \geq) b_{2}
\end{array}
$$

dengan

$x_{1}, x_{2}, \ldots, x_{n} \quad$ adalah variabel keputusan dari jenis kegiatan $n$.

$c_{1}, c_{2}, \ldots, c_{n} \quad$ adalah koefisien fungsi tujuan pemrograman linear.

$a_{11}, a_{2 n}, \ldots, a_{m n}$ adalah koefisien kendala dari kebutuhan sumber daya $m$ untuk menghasilkan setiap unit kegiatan $n$.

$b_{1}, b_{2}, \ldots, b_{m} \quad$ adalah sisi kanan kendala dari jumlah ketersediaan sumber daya $m$. $x_{1}, x_{2}, \ldots, x_{n} \geq 0$ adalah syarat non negatif untuk setiap variabel keputusan.

Pengubahan suatu bentuk model Matematika belum standar ke bentuk standar dapat dilakukan cara sebagai berikut:

1. Menambahkan variabel slack pada kendala bertanda $(\leq)$.

2. Menambahkan variabel surplus bernilai negatif dan artificial bernilai positif pada kendala bertanda $(\geq)$.

3. Menambahkan variabel artificial pada kendala bertanda (=).

[2]

Permasalahan pemrograman linear yang akan diselesaikan dengan algoritma titik interior terlebih dahulu diubah ke bentuk standar pemrograman linear. Iterasi dimulai dengan suatu nilai awal $\left(\widetilde{\mathrm{X}}^{\mathrm{k}}\right)$ yang memungkinkan sedemikian sehingga:

$$
\mathrm{A} \widetilde{\mathrm{X}}_{\mathrm{j}}^{\mathrm{k}}=\mathrm{B}
$$

dengan

$\boldsymbol{A} \quad$ adalah matriks koefisien kendala pemrograman linear.

$\widetilde{\boldsymbol{X}}_{j}^{k} \quad$ adalah variabel keputusan iterasi awal atau nilai interior fisibel.

$\boldsymbol{B} \quad$ adalah matriks vektor kolom sisi kanan kendala.

$\widetilde{\mathrm{X}}_{\mathrm{j}}^{\mathrm{k}}>0$ adalah syarat non negatif variabel keputusan atau nilai interior fisibel iterasi awal dimana $j=1,2, \ldots, n+m$ dan iterasi $k \in \mathbb{Z}^{+}$.

Langkah-langkah algoritma titik interior :

Algoritma proses optimasi menghasilkan nilai-nilai interior fisibel yang berurutan yaitu $\widetilde{\mathrm{X}}^{1}, \widetilde{\mathrm{X}}^{2}, \ldots, \widetilde{\mathrm{X}}^{\mathrm{k}}, \widetilde{\mathrm{X}}^{\mathrm{k}+1}, \ldots$

\section{Langkah 1 :}

Diketahui penyelesaian variabel keputusan percobaan awal $\left(\mathrm{x}_{1}\left[, \mathrm{x}_{2}, \ldots, \mathrm{x}_{\mathrm{n}+\mathrm{m}}\right)\right.$ yang berasal dari kendala akan dibentuk menjadi matriks diagonal $\boldsymbol{D}_{k+1}$.

Titik awal pemecahan $\widetilde{\mathrm{X}}^{0}=\left(\mathrm{x}_{1}\right.$ ? $\left., \mathrm{x}_{2}, \ldots, \mathrm{x}_{\mathrm{n}+\mathrm{m}}\right)$

$$
\mathrm{D}_{\mathrm{k}+1}=\left[\begin{array}{cccc}
\mathrm{x}_{1} & 0 & \cdots & 0 \\
0 & \mathrm{x}_{2} & \cdots & 0 \\
\vdots & \vdots & & \vdots \\
0 & 0 & \cdots & \mathrm{x}_{\mathrm{n}+\mathrm{m}}
\end{array}\right]
$$

Subtitusikan $\widetilde{\mathrm{X}}^{0}=\left(\mathrm{x}_{1}\right.$ ? $\left., \mathrm{x}_{2}, \ldots, \mathrm{x}_{\mathrm{n}+\mathrm{m}}\right)$ pada fungsi tujuan sehingga diperoleh $Z_{k}$ atau hasil iterasi awal.

\section{Langkah 2 :}

Hitung matriks koefisien kendala perubahan iterasi $k+1$

$\overline{\boldsymbol{A}}_{k+1}=\boldsymbol{A} \boldsymbol{D}_{k+1}$

dengan 
$\overline{\boldsymbol{A}}_{k+1} \quad$ adalah transformasi matriks antara matriks koefisien kendala dan matriks diagonal dari nilai interior $\widetilde{\boldsymbol{X}}^{k}$.

A adalah matriks koefisien kendala.

$\mathrm{D}_{\mathrm{k}+1}$ adalah matriks diagonal dari nilai interior $\widetilde{\boldsymbol{X}}^{k}$.

\section{Langkah 3} $k+1$

Hitung tingkat kemiringan matriks koefisien fungsi tujuan perubahan pada iterasi

$$
\overline{\boldsymbol{C}}_{k+1}=\boldsymbol{D}_{k+1} \boldsymbol{C}
$$

dengan

$\overline{\boldsymbol{C}}_{k+1}$ adalah tingkat kemiringan yang didapat dari perkalian matriks diagonal dan matriks koefisien fungsi tujuan.

$\boldsymbol{D}_{k+1}$ adalah matriks diagonal dari nilai interior $\widetilde{\boldsymbol{X}}^{k}$.

C adalah matriks koefisien fungsi tujuan.

\section{Langkah 4}

Hitung matriks proyeksi

$$
\boldsymbol{P}_{k+1}=\boldsymbol{I}-\overline{\boldsymbol{A}}_{k+1}{ }^{T}\left(\overline{\boldsymbol{A}}_{k+1} \overline{\boldsymbol{A}}_{k+1}{ }^{T}\right)^{-\mathbf{1}} \overline{\boldsymbol{A}}_{k+1}
$$

dengan

$\boldsymbol{P}_{k+1}$ adalah matriks proyeksi .

$\overline{\mathrm{A}}_{\mathrm{k}+1}^{\mathrm{T}}$ adalah transpose matriks koefisien kendala iterasi $k+1$.

$\overline{\mathrm{A}}_{\mathrm{k}+1} \quad$ adalah matriks koefisien kendala perubahan pada iterasi $k+1$.

I adalah matriks identitas.

\section{Langkah 5}

Menghitung tingkat kemiringan matriks koefisien fungsi tujuan yang diproyeksikan

$\boldsymbol{C} \boldsymbol{p}_{k+1}=\boldsymbol{P}_{k+1} \overline{\boldsymbol{C}}_{k+1}$

dengan

$\boldsymbol{C p}_{k+1}$ adalah matriks tingkat kemiringan yang diproyeksikan.

$\boldsymbol{P}_{k+1} \quad$ adalah matriks proyeksi.

$\overline{\boldsymbol{C}}_{k+1}$ adalah tingkat kemiringan matriks koefisien fungsi tujuan iterasi $k+1$.

\section{Langkah 6}

Menghitung penyelesaian percobaan perubahan iterasi $k+1$.

$$
\overline{\mathrm{X}}_{\mathrm{k}+1}=\left[\begin{array}{c}
1 \\
1 \\
\vdots \\
1
\end{array}\right]+\left(\frac{\alpha}{\mathrm{v}_{\mathrm{k}+1}}\right) \text { ] } \boldsymbol{C} \boldsymbol{p}_{k+1}
$$

dengan

$\overline{\boldsymbol{X}}_{k+1} \quad$ adalah penyelesaian percobaan setelah perubahan iterasi $k+1$.

$\alpha \quad$ adalah nilai absolut, $\alpha=0,95$.

$\boldsymbol{C}_{k+1}$ adalah matriks tingkat kemiringan yang diproyeksikan.

$V_{k+1} \quad$ adalah nilai mutlak minimum dari nilai $\boldsymbol{C} \boldsymbol{p}_{k+1} \cdot V_{k+1}=\operatorname{abs}\left(\min \left(\boldsymbol{C} \boldsymbol{p}_{k+1}\right)\right)$.

$k \quad$ adalah jumlah iterasi, untuk $k=0,1, \ldots, k+1$.

\section{Langkah 7}

Menghitung nilai interior untuk iterasi berikutnya.

$$
\widetilde{\mathrm{X}}^{\mathrm{k}+1} \text { 回 }=\boldsymbol{D} \overline{\boldsymbol{X}}_{k+1}
$$

dengan

$\widetilde{\mathrm{X}}^{\mathrm{k}+1} \quad$ adalah nilai interior iterasi $k+1$.

$\overline{\boldsymbol{X}}_{k+1}$ adalah penyelesaian percobaan setelah perubahan iterasi $k+1$.

Subtitusikan nilai interior $\widetilde{\mathrm{X}}^{\mathrm{k}+1}$ pada fungsi tujuan sehingga diperoleh nilai $Z_{k+1}$.

\section{Langkah 8 :}

Proses iterasi akan berhenti apabila kriteria berhenti terpenuhi yaitu

$$
Z_{k+1} \leq Z_{k}
$$

Jika nilai $Z_{k+1} \geq Z_{k}$ maka dilakukan iterasi selanjutnya. Apabila proses iterasi telah berhenti maka telah didapat solusi optimal.

dengan 
$Z_{k+1}$ adalah nilai fungsi tujuan hasil subtitusi $\widetilde{\mathrm{X}}^{\mathrm{k}+1}$ (nilai iterasi $k+1$ ).

$Z_{k} \quad$ adalah nilai fungsi tujuan hasil subtitusi $\widetilde{\mathrm{X}}^{\mathrm{k}}$.

Solusi pemrograman linear yang diperoleh dengan algoritma titik interior dilakukan analisis sensitivitas untuk memberikan informasi terhadap penentuan harga jual produk olahan nanas dengan:

a. Analisis perubahan koefisien fungsi tujuan untuk variabel bukan dasar.

b. Analisis perubahan koefisien fungsi tujuan untuk variabel dasar.

c. Analisis perubahan sisi kanan kendala.

Tahap akhir adalah menganalisis hasil optimasi produksi dan analisis sensitivitas yang telah diperoleh dari penelitian.

\section{Hasil dan Pembahasan}

\subsection{Deskripsi Data Observasi}

UP2K Melati memproduksi makanan ringan berbahan baku nanas antara lain dodol nanas, wajik nanas, manisan nanas dan keripik nanas. Harga yang ditawarkan untuk dodol nanas, wajik nanas, dan manisan nanas yaitu Rp 10.000,00/250 gram serta keripik nanas seharga $\operatorname{Rp} 15.000,00 / 250$ gram.

Produksi makanan ringan berbahan baku nanas memerlukan komposisi dari berbagai bahan baku seperti yang diuraikan pada Tabel. 1 sebagai berikut:

Tabel 1. Data Bahan Baku dan Persediaan Bahan Baku

\begin{tabular}{|c|c|c|c|c|c|c|}
\hline \multirow[b]{2}{*}{ No. } & \multirow{2}{*}{$\begin{array}{c}\text { Jenis } \\
\text { Bahan } \\
\text { Produksi }\end{array}$} & \multicolumn{4}{|c|}{ Jumlah Bahan Tiap Produk } & \multirow{2}{*}{$\begin{array}{c}\text { Persediaan } \\
\text { Bahan } \\
\text { Baku } \\
\end{array}$} \\
\hline & & $\begin{array}{c}\text { Dodol } \\
\text { Nanas }\end{array}$ & $\begin{array}{c}\text { Wajik } \\
\text { Nanas }\end{array}$ & $\begin{array}{c}\text { Manisan } \\
\text { Nanas }\end{array}$ & $\begin{array}{c}\text { Keripik } \\
\text { Nanas }\end{array}$ & \\
\hline 1. & Nanas & $210 \mathrm{Kg}$ & $135 \mathrm{Kg}$ & - & $67,5 \mathrm{Kg}$ & $412,5 \mathrm{Kg}$ \\
\hline 2. & Gula & $13 \mathrm{Kg}$ & $8 \mathrm{Kg}$ & $4 \mathrm{Kg}$ & - & $25 \mathrm{Kg}$ \\
\hline 3. & $\begin{array}{l}\text { Tepung } \\
\text { Ketan }\end{array}$ & $3 \mathrm{Kg}$ & - & - & - & $5 \mathrm{Kg}$ \\
\hline 4. & $\begin{array}{l}\text { Tepung } \\
\text { Terigu }\end{array}$ & $3 \mathrm{Kg}$ & - & - & - & $6 \mathrm{Kg}$ \\
\hline 5. & Kelapa & - & $15 \mathrm{Kg}$ & - & - & $15 \mathrm{Kg}$ \\
\hline 6. & Garam & - & $0,2 \mathrm{Kg}$ & - & - & $1 \mathrm{Kg}$ \\
\hline 7. & Agar-agar & - & $0,028 \mathrm{Kg}$ & $0,07 \mathrm{Kg}$ & - & $0,105 \mathrm{Kg}$ \\
\hline 8. & $\begin{array}{l}\text { Minyak } \\
\text { Goreng }\end{array}$ & - & - & - & $3,5 \mathrm{Kg}$ & $15 \mathrm{Kg}$ \\
\hline 9. & Air Nanas & - & - & $4,5 \mathrm{~L}$ & - & $4,5 \mathrm{~L}$ \\
\hline
\end{tabular}

Sumber : UP2K Melati, Kota Prabumulih

Jumlah nanas yang dibutuhkan untuk produksi sebanyak 412,5 Kg nanas selanjutnya diolah sehingga menghasilkan produk olahan nanas dengan berat satuan 250 gram dengan rincian dodol nanas sebanyak 150 kotak, wajik nanas sebanyak 100 kotak, manisan nanas sebanyak 65 plastik, dan keripik nanas sebanyak 30 plastik. Data bahan baku pada Tabel 1. dihitung sesuai produk yang telah dihasilkan per kemasan 250 gram dan diuraikan pada Tabel 2.

Tabel 2. Data Bahan Baku per Kemasan 250 gr Hasil Produksi

\begin{tabular}{|c|c|c|c|c|c|c|}
\hline \multirow[b]{2}{*}{ No. } & \multirow{2}{*}{$\begin{array}{c}\text { Jenis } \\
\text { Bahan } \\
\text { Produksi }\end{array}$} & \multicolumn{4}{|c|}{$\begin{array}{c}\text { Jumlah Bahan Tiap Produk } \\
\text { per Kemasan } 250 \text { gr }\end{array}$} & \multirow{2}{*}{$\begin{array}{c}\text { Persediaan } \\
\text { Bahan } \\
\text { Baku }\end{array}$} \\
\hline & & $\begin{array}{l}\text { Dodol } \\
\text { Nanas }\end{array}$ & $\begin{array}{c}\text { Wajik } \\
\text { Nanas }\end{array}$ & $\begin{array}{c}\text { Manisan } \\
\text { Nanas }\end{array}$ & $\begin{array}{c}\text { Keripik } \\
\text { Nanas }\end{array}$ & \\
\hline 1. & Nanas & $1,4 \mathrm{Kg}$ & $1,35 \mathrm{Kg}$ & - & $2,25 \mathrm{Kg}$ & $412,5 \mathrm{Kg}$ \\
\hline
\end{tabular}




\begin{tabular}{|c|l|c|c|c|c|c|}
\hline 2. & Gula & $0,087 \mathrm{Kg}$ & $0,08 \mathrm{Kg}$ & $0,062 \mathrm{Kg}$ & - & $25 \mathrm{Kg}$ \\
\hline 3. & $\begin{array}{l}\text { Tepung } \\
\text { Ketan }\end{array}$ & $0,02 \mathrm{Kg}$ & - & - & - & $5 \mathrm{Kg}$ \\
\hline 4. & $\begin{array}{l}\text { Tepung } \\
\text { Terigu }\end{array}$ & $0,02 \mathrm{Kg}$ & - & - & - & $6 \mathrm{Kg}$ \\
\hline 5. & Kelapa & - & $0,15 \mathrm{Kg}$ & - & - & $15 \mathrm{Kg}$ \\
\hline 6. & Garam & - & $0,002 \mathrm{Kg}$ & - & - & $1 \mathrm{Kg}$ \\
\hline 7. & Agar-agar & - & $0,00028 \mathrm{Kg}$ & $0,0011 \mathrm{Kg}$ & - & $0,105 \mathrm{Kg}$ \\
\hline 8. & $\begin{array}{l}\text { Minyak } \\
\text { Goreng }\end{array}$ & - & - & - & $0,117 \mathrm{Kg}$ & $15 \mathrm{Kg}$ \\
\hline 9. & Air Nanas & - & - & $0,069 \mathrm{~L}$ & - & $4,5 \mathrm{~L}$ \\
\hline
\end{tabular}

Berdasarkan Tabel 2 ada 9 jenis bahan baku yang diperlukan dalam produksi tiap produk olahan nanas per kemasan 250 gram. Persediaan nanas sebanyak 412,5 Kg dalam produksi diperlukan sejumlah 1,4 Kg untuk dodol nanas per kemasan 250 gram, dan wajik nanas sejumlah 1,35 Kg per kemasan 250 gram, serta keripik nanas sejumlah 2,25 Kg tiap kemasan 250 gram.

Proses produksi memiliki alokasi waktu untuk produksi yaitu 40 jam dengan tenaga kerja sebanyak 4 orang. Proses pengerjaan untuk satu produk dilakukan dalam 1 hari dimulai dari pukul 07.00 WIB hingga pukul 18.00 WIB. Data proses produksi tiap produk per kemasan 250 gram akan dijelaskan pada Tabel 3.

Tabel 3. Data Waktu Proses Produksi Tiap Produk per Kemasan 250 gr

\begin{tabular}{|c|c|c|c|c|c|c|}
\hline \multirow{2}{*}{ No. } & \multirow{2}{*}{ Proses Produksi } & \multicolumn{4}{|c|}{$\begin{array}{l}\text { Waktu yang Diperlukan Tiap Produk per } \\
\text { Kemasan } 250 \text { gr (menit) }\end{array}$} & \multirow{2}{*}{$\begin{array}{c}\text { Waktu } \\
\text { yang } \\
\text { Tersedia } \\
\text { (menit) }\end{array}$} \\
\hline & & $\begin{array}{l}\text { Dodol } \\
\text { Nanas }\end{array}$ & $\begin{array}{l}\text { Wajik } \\
\text { Nanas }\end{array}$ & $\begin{array}{c}\text { Manisan } \\
\text { Nanas }\end{array}$ & $\begin{array}{c}\text { Keripik } \\
\text { Nanas }\end{array}$ & \\
\hline 1. & Pengupasan Kulit Nanas & 1,2 & 1,2 & - & 2 & 600 \\
\hline 2. & Pembuangan Mata Nanas & 1 & 1,2 & - & 2 & 300 \\
\hline 3. & Pemotongan & 0,03 & 0,07 & - & 0,15 & 30 \\
\hline 4. & Pencucian Nanas & 0,03 & 0,05 & - & 0,17 & 15 \\
\hline 5. & Pencucian Irisan Mata Nanas & - & - & 0,046 & - & 5 \\
\hline 6. & Pemarutan nanas & 0,17 & 0,12 & - & - & 60 \\
\hline 7. & $\begin{array}{l}\text { Penghalusan Irisan Mata } \\
\text { Nanas }\end{array}$ & - & - & 0,07 & - & 15 \\
\hline 8. & Pemasakan & 0,8 & 1,2 & 0,23 & - & 360 \\
\hline 9. & Penimbangan berat & - & - & - & 0,17 & 30 \\
\hline 10. & Penggorengan & - & - & - & 4 & 600 \\
\hline 11. & Pengadukan & 2,4 & 3,6 & - & - & 1.080 \\
\hline 12. & Pencetakan & 0,3 & 0,3 & 0,46 & - & 120 \\
\hline 13. & Penjemuran & - & - & 155 & - & 14.400 \\
\hline 14. & Pengeringan Minyak & - & - & - & 0,1 & 30 \\
\hline 15. & Pengemasan & 1,2 & 1,2 & 1,4 & 3 & 900 \\
\hline
\end{tabular}




\begin{tabular}{|c|l|c|c|c|c|c|}
\hline 16. & Pemasaran & 9,6 & 14,4 & 22,2 & 48 & 43.200 \\
\hline
\end{tabular}

Data biaya produksi yang dikeluarkan untuk memproduksi dodol nanas per kemasan sebesar Rp 7.240,00. biaya produksi wajik per kemasan 250 gram sebesar Rp 7.345,00., biaya produksi manisan nanas per kemasan 250 gr sebesar Rp 2.623,00, serta data biaya produksi keripik nanas sebesar Rp 9.767,00 per kemasan 250 gram. Keuntungan masing-masing produk per kemasan 250 gram diuraikan pada Tabel 4.

Tabel 4. Keuntungan Tiap Produk per Kemasan 250 gr

\begin{tabular}{|c|c|c|}
\hline No. & Jenis Produk & $\begin{array}{c}\text { Keuntungan Produk per } \\
\text { Kemasan 250 gr } \\
\text { (Rupiah) }\end{array}$ \\
\hline 1. & Dodol Nanas & 399 \\
\hline 2. & Wajik Nanas & 285 \\
\hline 3. & Manisan Nanas & 5.007 \\
\hline 4. & Keripik Nanas & 2.863 \\
\hline
\end{tabular}

\subsection{Pengolahan Data}

Bentuk model pemrograman linear optimasi produksi di Unit Peningkatan Penghasilan Keluarga (UP2K) Melati, Prabumulih. Bentuk model pemrograman linear adalah sebagai berikut:

Fungsi tujuan: Memaksimumkan $Z=399 x_{1}+285 x_{2}+5.007 x_{3}+2.863 x_{4}$

dengan kendala $1,4 x_{1}+1,35 x_{2}+2,25 x_{4} \leq 412,5$

$$
\begin{aligned}
& 0,087 x_{1}+0,08 x_{2}+0,062 x_{3} \leq 25 \\
& 0,02 x_{1} \leq 5 \\
& 0,02 x_{2} \leq 1 \\
& 0,00028 x_{2}+0,0011 x_{3} \leq 0,105 \\
& 0,117 x_{4} \leq 15 \\
& 0,069 x_{3} \leq 4,5 \\
& x_{1}+1,2 x_{2}+2 x_{4} \leq 300 \\
& 155 x_{3} \leq 14.400 \\
& 0,17 x_{1}+0,12 x_{2} \leq 60 \\
& 0,8 x_{1}+1,2 x_{2}+0,23 x_{3} \leq 360 \\
& 4 x_{4} \leq 600 \\
& 1,2 x_{1}+1,2 x_{2}+1,4 x_{3}+3 x_{4} \leq 900 \\
& x_{1}, x_{2}, x_{3}, x_{4} \geq 0
\end{aligned}
$$

Bentuk model pemrograman linear yang terbentuk pada Persamaan (11) diperiksa menggunakan aplikasi LINDO. Pengubahan pemrograman linear Persamaan (11) ke bentuk standar pemrograman linear dengan menambahkan variabel slack $\left(x_{5}, x_{6}, \ldots, x_{17}\right)$ sehingga terbentuk kendala persamaan sebagai berikut:

Fungsi tujuan: Memaksimumkan

$$
\begin{aligned}
& Z=399 x_{1}+285 x_{2}+5.007 x_{3}+2.863 x_{4}+0 x_{5}+0 x_{6}+0 x_{7}+0 x_{8}+0 x_{9}+0 x_{10}+0 x_{11}+ \\
& 0 x_{12}+0 x_{13}+0 x_{14}+0 x_{15}+0 x_{16}+0 x_{17} \\
& \text { dengan kendala } \\
& \quad 1,4 x_{1}+1,35 x_{2}+2,25 x_{4}+x_{5}=412,5 \\
& \quad 0,087 x_{1}+0,08 x_{2}+0,062 x_{3}+x_{6}=25 \\
& \quad 0,02 x_{1}+x_{7}=5 \\
& \quad 0,02 x_{2}+x_{8}=1 \\
& \quad 0,00028 x_{2}+0,0011 x_{3}+x_{9}=0,105 \\
& \quad 0,117 x_{4}+x_{10}=15 \\
& \quad 0,069 x_{3}+x_{11}=4,5 \\
& \quad x_{1}+1,2 x_{2}+2 x_{4}+x_{12}=300 \\
& 155 x_{3}+x_{13}=14.400 \\
& \quad 0,17 x_{1}+0,12 x_{2}+x_{14}=60 \\
& \quad 0,8 x_{1}+1,2 x_{2}+0,23 x_{3}+x_{15}=360
\end{aligned}
$$




$$
\begin{aligned}
& 4 x_{4}+x_{16}=600 \\
& 1,2 x_{1}+1,2 x_{2}+1,4 x_{3}+3 x_{4}+x_{17}=900 \\
& x_{1}, x_{2}, x_{3}, x_{4}, x_{5}, x_{6}, x_{7}, x_{8}, x_{9}, x_{10}, x_{11}, x_{12}, x_{13}, x_{14}, x_{15}, x_{16} x_{17} \geq 0
\end{aligned}
$$

\section{Penyelesaian Pemrograman Linear Menggunakan Algoritma Titik Interior}

Permasalahan pemrograman linear optimasi produksi tiap produk olahan nanas dengan mengaplikasikan algoritma titik interior mencapai solusi optimal saat kriteria pemberhentian $Z\left(\widetilde{\boldsymbol{X}}^{k+1}\right) \leq Z\left(\widetilde{\boldsymbol{X}}^{k}\right)$. Nilai interior proses penyelesaian menggunakan algoritma titik interior diuraikan pada Tabel (5).

Tabel 5. Nilai Interior dan Nilai Z Tiap Iterasi Algoritma Titik Interior

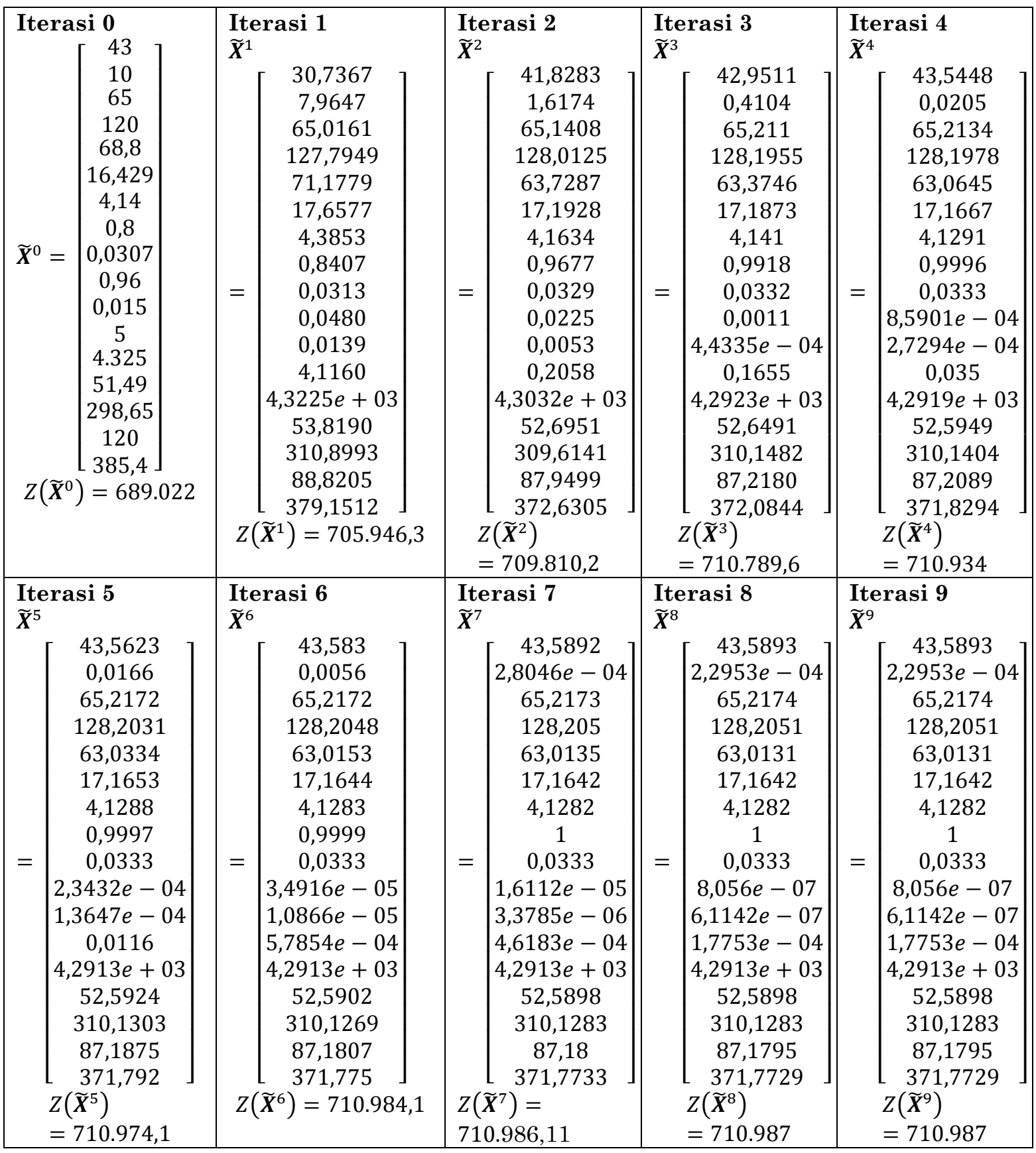

Nilai fungsi tujuan iterasi 9 diperoleh $Z\left(\widetilde{X}^{9}\right)=710.987$ dan nilai fungsi tujuan iterasi 8 sebesar $Z\left(\widetilde{\boldsymbol{X}}^{8}\right)=710.987$. Kriteria pemberhentian pada iterasi 9 telah terpenuhi $Z\left(\widetilde{\boldsymbol{X}}^{9}\right) \leq Z\left(\widetilde{\boldsymbol{X}}^{8}\right)$ sehingga proses iterasi perhitungan menggunakan algoritma titik interior 
dihentikan. Keuntungan maksimal produk makanan ringan yang diproduksi dalam satu kali produksi sebesar Rp 710.987,00.

Produk yang seharusnya diproduksi adalah dodol nanas $\left(x_{1}\right)$ sejumlah 43 kemasan/250 gram, manisan nanas $\left(x_{3}\right)$ sejumlah 65 kemasan/250 gram, dan keripik nanas $\left(x_{4}\right)$ sejumlah 128 kemasan/250 gram. Produk wajik nanas pada solusi optimal merupakan variabel bukan dasar (variabel non basis) sehingga produk wajik nanas direkomendasikan tidak wajib untuk diproduksi, karena tidak meningkatkan keuntungan produksi.

\section{Simpulan}

Keuntungan maksimum produk makanan ringan olahan nanas yang diproduksi dalam satu kali produksi sebesar $\mathrm{Rp} 710.987,00$. Produk yang seharusnya diproduksi adalah dodol nanas $\left(x_{1}\right)$ sejumlah 43 kemasan/250 gram, manisan nanas $\left(x_{3}\right)$ sejumlah 65 kemasan/250 gram, dan keripik nanas $\left(x_{4}\right)$ sejumlah 128 kemasan/250 gram.

Hasil analisis sensitivitas pada solusi keuntungan produksi:

a. Produk wajik nanas $\left(x_{2}\right)$ tidak direkomendasikan untuk diproduksi, karena keuntungan produk wajik nanas per kemasan 250 gram hanya sebesar Rp 285,00. Jika keuntungan produk wajik nanas per kemasan 250 gram $\left(c_{2}\right)$ ditingkatkan dalam interval $0-193,8$ atau jika keuntungan diantara $\mathrm{Rp} 285,00$ hingga $\mathrm{Rp} 478,8$ maka produksi akan optimal.

b. Jumlah produksi dodol nanas $\left(x_{1}\right)$, manisan nanas $\left(x_{3}\right)$, dan keripik nanas $\left(x_{4}\right)$ telah optimal dan tidak memerlukan penambahan jumlah produksi

\section{Daftar Pustaka}

1. Adrianto, T.S. 2006. Perancangan Program Optimalisasi Keuntungan Produksi dengan Metode Karmakar (Studi Kasus: Tan Garment). Skripsi. Jakarta: Fakultas Teknik Informatika - Matematika Universitas Bina Nusantara.

2. Aminudin. 2005. Prinsip-prinsip Riset Operasi. Jakarta: Erlangga.

3. Anton, H \& Rorres, C. 1996. Aljabar Linear Elementer. Versi Aplikasi. Edisi Kedelapan Jilid I. Bandung: Erlangga.

4. Dimyati, T.T. dan A. Dimyati. 1992. Operations Research: Model-model Pengambilan Keputusan. Cetakan Kedua. Bandung: PT. Sinar Baru Algensindo.

5. Humairoh, N. 2012. Kelompok Usaha Pangan Olahan Nanas Melati, Prabumulih. (http://kelompokusahamelati.blogspot.com). Diakses pada tanggal 13 September 2014 jam 20.23 WIB.

6. Nurhayati. 2009. Algoritma Titik Interior untuk Menyelesaikan Masalah Program Linear. Skripsi. Yogyakarta: Fakultas Sains dan Teknologi UIN Sunan Kalijaga.

7. Rangkuti, A. 2012. 7 Model Riset Operasi \& Aplikasinya. Surabaya: Brilian Internasional.

8. Suparno. 2009. Penyelesaian Program Linear dengan Menggunakan Algoritma Titik Interior dan Metode Simpleks. Skripsi. Surakarta: Fakultas Matematika dan Ilmu Pengetahuan Alam Universitas Sebelas Maret.

9. Supranto, J. 1983. Linear Programming. Jakarta: Fakultas Ekonomi Universitas Indonesia.

10. Suwandi, N. 2012. Aplikasi Metode Simpleks pada Produksi Padi di Kabupaten Ogan Ilir serta Analisis Kelayakan Produksi Secara Sensitivitas. Skripsi. Indralaya: Universitas Sriwijaya. (Tidak dipublikasikan)

11. Winarti, N.D. 2007. Optimasi Pemrograman Kuadratik dengan Menggunakan Algoritma Primal - Dual Interior Point. Skripsi. Surabaya: Fakultas Teknologi Informasi Institut Teknologi Sepuluh Nopember.

12. Winston, L.W. 1987. Operations Research: Applications and Algorithms. Boston: PWS-Kent Publishing Company. 
Tiara, et al / JMI Vol 11 No 1 April 2015, Pp. 75 - 84 